\title{
Letter to the Editor concerning: "Inguinal hernia in neonates and ex-preterm: complications, timing and need for routine contralateral exploration"
}

\author{
Belén Aneiros Castro ${ }^{1}$ (1) - Indalecio Cano Novillo ${ }^{2}$. Araceli García Vázquez ${ }^{2}$
}

Accepted: 6 June 2019 / Published online: 13 June 2019

๑) Springer-Verlag GmbH Germany, part of Springer Nature 2019

\section{Dear Editor:}

We read with interest the article by Pini Prato et al. that investigated the outcomes of open inguinal hernia repair in neonates and ex-preterm babies weighing less than $5 \mathrm{~kg}$. The authors performed 184 herniotomies in 154 patients (male to female ratio 4.5:1) [1]. We would like to congratulate the authors on their work; however, we have found several mistakes.

First, the authors observed 20 complications in overall 184 herniotomies and a rate of complications of $9.8 \%$. However, when we recalculated this rate, we found a rate of $10.9 \%$ (20/184). Second, they reported the rate of testicular atrophy, hydrocele and testicular ascent taking into account all hernia repairs, including the girls. We think that the rate of should testicular atrophy, hydrocele and testicular ascent should be calculated taking into account not the number of all the patients, but the number of inguinal repairs in males. Therefore, these rates should be greater than those reported. Finally, their rate of recurrence was $4.5 \%$ (8/184), but when we recalculated this rate, we found a rate of $4.3 \%$.

Surprisingly, we observed similar mistakes in other papers [2-5]. Some authors calculated the rate of postoperative complications such as hydrocele, testicular atrophy or high testes without excluding female patients $[2,3]$. On the other hand, several authors calculated the recurrence rate

This comment refers to the article available at https://doi. org/10.1007/s00383-014-3638-z.

Belén Aneiros Castro

belenaneiroscastro@gmail.com

1 Department of Pediatric Surgery, Hospital Álvaro Cunqueiro, Calle de Clara Campoamor, 341, 36312 Vigo, Spain

2 Department of Pediatric Surgery, Hospital 12 de Octubre, Madrid, Spain based on the number of patients [2-5]. We think that recurrence rate should be calculated taking into account not the number of patients, but the number of inguinal repairs.

As a consequence of these discrepancies, many studies are not comparable, making it impossible to perform a metaanalysis. In the era of laparoscopic surgery, it seems interesting to us to improve the accuracy of these comparisons. Therefore, we would like to highlight the need of strict formulas to calculate these rates of postoperative complications. We again thank the authors for their contribution.

\section{References}

1. Pini Prato A, Rossi V, Mosconi M et al (2015) Inguinal hernia in neonates and ex-preterm: complications, timing and need for routine contralateral exploration. Pediatr Surg Int 31:131-136

2. Nagraj S, Sinha S, Grant H, Lakhoo K, Hitchcock R, Johnson P (2006) The incidence of complications following primary inguinal herniotomy in babies weighing $5 \mathrm{~kg}$ or less. Pediatr Surg Int 22:500-502

3. Esposito C, Turial S, Escolino M et al (2012) Laparoscopic inguinal hernia repair in premature babies weighing $3 \mathrm{~kg}$ or less. Pediatr Surg Int 28:989-992

4. Shalaby R, Abd Alrazek M, Elsaied A et al (2018) Fifteen years experience with laparoscopic inguinal hernia repair in infants and children. J Laparoendosc Adv Sur Tech 28:101-105

5. Darmawan KF, Sinclair T, Dunn JCY (2018) Comparison of laparoscopic and open pediatric inguinal hernia repairs at two institutions. Pediatr Surg Int 34:1293-1298

Publisher's Note Springer Nature remains neutral with regard to jurisdictional claims in published maps and institutional affiliations. 